\title{
Demographic and clinical profiles of female patients diagnosed with breast cancer in Iraq
}

\author{
Nada A.S. Alwan, Furat N. Tawfeeq, and Nawar A.G. Mallah
}

National Cancer Research Center, University of Baghdad, Baghdad, Iraq.

*Correspondence to Nada A.S. Alwan (email:nadalwan@yahoo.com).

(Submitted: 28 November 2018 - Revised version received: 13 December 2018 - Accepted: 18 January 2019 - Published online: 26 February 2019)

\begin{abstract}
Objective To highlight the main demographic characteristics and clinical profiles of female patients registered with breast cancer in Iraq; focusing on the impact of age.

Methods This retrospective study enrolled 1172 female patients who were diagnosed with breast cancer at the Main Center for Early Detection of Breast Cancer/Medical City Teaching Hospital in Baghdad. Data were extracted from an established information system, developed by the principal author under supervision of WHO, that was based on valid clinical records of Iraqi patients affected by breast cancer. The recorded information regarding clinical examination comprised positive palpable lumps, bloody nipple discharge, skin changes, bilateral breast involvement, tumor size, lymph node status, and the stage of the disease.

Results The mean age at the presentation was 51 years; patients under the age of 50 constituted $46.8 \%$. Overall $9.8 \%$ were not married, $22.4 \%$ were illiterate whereas $19.2 \%$ graduated from universities. About $72 \%$ of the patients had more than two children, merely $7.5 \%$ delivered their first child after the age of 35 years and only $11 \%$ were nulliparous. History of lactation and hormonal therapy was recorded in $57.6 \%$ and $19.4 \%$ respectively. Family history of cancer was positive in $28.8 \%$ and breast cancer specifically in $18.7 \%$. Clinically, the most common presenting symptom was breast lumps (95\%) followed by skin changes/ulcerations (6.7\%) and bloody nipple discharge (4.3\%). Bilateral breast involvement was encountered in 4.7\%. More than two-thirds of the patients (68.2\%) had palpable axillary lymph nodes; classifying 40.5\% into advanced stages III and IV. In general stages I-IV comprised 12\%, 47.5\%, 31.9\%, and 8.6\% respectively. Upon stratifying the studied sample with respect to age at diagnosis, it was observed that the frequency of unmarried patients was significantly higher among younger women under the age of 50 years, whereas illiteracy and nulliparity features were statistically lower $(p<0.05)$.

Conclusion A considerable proportion of breast cancer patients in Iraq still present with locally advanced disease at the time of diagnosis. That justifies the necessity to promote public awareness educational campaigns to strengthen our national early detection program. Excluding the marital status, level of education and number of parity, there was no statistical difference regarding the impact of age on the demographic and clinical profiles of breast cancer among premenopausal versus postmenopausal Iraqi patients.

Keywords demographic, clinical, profiles, breast, cancer, Iraq
\end{abstract}

\section{Introduction}

The latest WHO estimates reveal that breast cancer is the most prevalent malignancy worldwide in 154 out of 185 countries and is the leading cause of cancer related mortality in more than 100 countries. Globally, it remains the most common cancer among women accounting for $25 \%$ of the registered female cancers; with approximately 2.1 million newly diagnosed cases in 2018. ${ }^{1}$ The variations in the incidence rates are often attributable to higher prevalence of risk factors specifically among transitioning regions in South America, Africa, and Asia. ${ }^{2}$

Apart from genetic predisposition, many other factors could have an impact on developing breast cancer among women including demographic characteristics, clinical, reproductive, and environmental features. Increased risk has been associated with advanced age, positive family history, socioeconomic status, diet, endogenous or exogenous hormones, atypical breast diseases, benign tumors, oncogenic viruses, and carcinogenic exposures.

In Iraq, breast cancer ranks the first among the top ten malignant neoplasms affecting the community; comprising $19.5 \%$ of total (4996 cases) and $34.3 \%$ of female cancers (4922 cases). During 2016, 897 women died from that disease which is the registered as the first cause of cancer related mortality among Iraqi females $(23.6 \%)$ and the second overall among males and females (12.1\%) after bronchogenic cancer. ${ }^{4,5}$ Previous cross-sectional studies revealed a considerable lack of knowledge regarding the risk factors for breast cancer in Iraq even among the educated strata of the society. ${ }^{6}$
WHO introduced guidelines for establishing national strategies to control cancer in the Eastern Mediterranean Region (EMR). ${ }^{7}$ Focusing on breast cancer, information on the putative risk factors for the disease and the clinical characteristics of the affected patients are of utmost importance to plan for its early detection and control. Within that context, an Iraqi National Breast Cancer Research Program was established in 2010; through which a comprehensive information system database was developed for patients diagnosed with the disease in collaboration with the International Agency for Research on Cancer (IARC)/WHO. ${ }^{8}$ Based on that, several studies have documented that Iraqi females often present with breast cancer at younger ages, advanced stages and with more aggressive behavior than their Western counterparts. ${ }^{9-13}$ In a recent comparative survey, it was demonstrated that the significant differences in the clinical and tumor characteristics between Iraqi and British patients persisted even after adjusting for age among patients younger than 50 years. ${ }^{14}$

The aim of this study was to highlight the main demographic and clinical profiles of breast cancer among a series of Iraqi female patients who were registered with that disease at a main specialized center; focusing on the impact of age.

\section{Materials and Methods}

This retrospective study enrolled 1172 female patients who were diagnosed with breast cancer at the Referral Training 
Center for Early Detection of Breast Tumors, Medical City Teaching Hospital in Baghdad over a 4-year period from 2014 to 2017. All related data was introduced through an established information system database, developed by the principal author under supervision of IARC, at the National Cancer Research Center of Baghdad University. That was part of a designed ongoing National Breast Cancer Research Project to document the demographic, clinical and pathological characteristics of Iraqi breast cancer patients. ${ }^{12}$ The analyzed data was based on the information recorded in the file sheet questionnaires and clinical records of the referred patients.

The ethical approval was initially obtained by the Ethical Research Committee of the National Cancer Research Center according to the ethical standards laid down by the Declaration of Helsinki. The study protocol is within the framework of a Regional Comparative Breast Cancer Research Project, approved by the IARC Ethics Committee, WHO in 2016.

The studied demographic and clinical data included age, marital status, educational background, number of parity, age at first child birth, history of lactation, hormonal therapy, and family history of breast cancer or any other malignancy. Only complete valid followed up cases comprising all requested data were included in the clinical presentation part of the study. The recorded variables were positive palpable lumps, bloody nipple discharge, skin changes or ulcerations, bilateral breast involvement, tumor size, lymph node involvement, and the stage of the disease. The clinical stage of breast cancer was defined according to UICC TNM Classification System $^{15}$ and the American Joint Committee on Cancer Staging. ${ }^{16}$

\section{Statistical Analysis}

Data entry was performed using the statistical program (SPSS), version No. 23. The findings were statistically analyzed and the digital frequencies and percentages were calculated accordingly. Results were considered statistically significant when $p$-value was $\leq 0.05$.

\section{Results}

Table 1 illustrates the demographic characteristics and clinical history of 1172 female breast cancer patients. The peak frequency occurred among the age groups (35-49) years and (60-64) years. Only $4.4 \%$ and $11 \%$ were diagnosed before the age of 35 and after 64 years respectively. About $10 \%$ were single, $22.4 \%$ were illiterate, $10.8 \%$ were nulliparous whereas $>71 \%$ had more than two children. Only $7.5 \%$ had their first child birth after the age of 35 years. History of lactation was recorded in $57.6 \%$, hormonal intake in $19.4 \%$, and cancer in $28.8 \%$. On the other hand, family history of breast cancer specifically was displayed in $18.7 \%$.

Clinically, 95\% presented with palpable lumps, 4.3\% complained of bloody nipple discharge while $6.7 \%$ had overlying skin changes and ulcerations. Bilateral malignant involvement of the breast was noted in $4.7 \%$. Approximately $59 \%$ had a tumor size measuring $2-5 \mathrm{~cm}$ (T2), more than $68 \%$ had lymph node involvement at the time of initial presentation; thus classifying $40.5 \%$ of patients into stages III and IV (Table 2).

In Tables 3 and 4 , the patients were stratified according to age into those $<50$ years versus those aged $\geq 50$ years. A statistical

\begin{tabular}{|c|c|}
\hline Variable & Patients \\
\hline Age range (years)* & $18-90$ \\
\hline Mean (SD) & $51(10.68)$ \\
\hline Age category & $N(\%)$ \\
\hline $20-34$ & $52(4.4)$ \\
\hline $35-49$ & $497(42.4)$ \\
\hline $50-64$ & $494(42.2)$ \\
\hline$\geq 65$ & $129(11.0)$ \\
\hline \multicolumn{2}{|l|}{ Marital status* } \\
\hline Single & $115(9.8)$ \\
\hline Married & $1032(88)$ \\
\hline Divorced & $12(1.0)$ \\
\hline Widow & $13(1.1)$ \\
\hline \multicolumn{2}{|l|}{ Educational status* } \\
\hline Illiterate & $262(22.4)$ \\
\hline Primary school & $355(30.3)$ \\
\hline Secondary school & $271(23.1)$ \\
\hline University and over & $225(19.2)$ \\
\hline Unknown & $59(5.0)$ \\
\hline \multicolumn{2}{|l|}{ Parity $^{* *}$} \\
\hline Nulliparous & $115(10.8)$ \\
\hline $1-2$ & $180(17.0)$ \\
\hline $3-5$ & $496(47.0)$ \\
\hline$\geq 6$ & $266(25.1)$ \\
\hline \multicolumn{2}{|l|}{ Age at first child ${ }^{* * *}$} \\
\hline$<20$ & $257(27.3)$ \\
\hline $20-29$ & $466(49.5)$ \\
\hline $30-35$ & $124(13.1)$ \\
\hline$>35$ & $71(7.5)$ \\
\hline Unknown & $24(2.5)$ \\
\hline \multicolumn{2}{|l|}{ Lactation ${ }^{* * *}$} \\
\hline Yes & $543(57.6)$ \\
\hline No & $399(42.4)$ \\
\hline \multicolumn{2}{|l|}{ Hormonal therapy* } \\
\hline Yes & $227(19.4)$ \\
\hline No & $945(80.6)$ \\
\hline \multicolumn{2}{|c|}{ Family history (any cancer) $^{*}$} \\
\hline Yes & $337(28.8)$ \\
\hline No & $835(71.2)$ \\
\hline \multicolumn{2}{|c|}{ Family history (breast cancer) ${ }^{*}$} \\
\hline Yes & $219(18.7)$ \\
\hline No & $953(81.3)$ \\
\hline
\end{tabular}

${ }^{*}$ Number of patients $=1172$.

"Number of patients $=1057$ (Unmarried are excluded).

$* *$ Number of patients $=942$ (Unmarried and Nulliparous are excluded).

difference was noted regarding marital status, level of education, and parity. The frequency of unmarried patients was significantly higher among younger women under the age of 50 years, whereas illiteracy and nulliparity features were statistically lower $(p<0.05)$.

On the other hand, no statistical difference was observed with respect to the clinical presentation of the examined patients including palpable lumps, bloody nipple discharge, skin changes, tumor size, lymph node status and the stage of the disease (Table 4). 


\begin{tabular}{|c|c|}
\hline \multirow[t]{2}{*}{ Variable } & Patients \\
\hline & $N(\%)$ \\
\hline \multicolumn{2}{|c|}{ Palpable lump* } \\
\hline Yes & $543(95)$ \\
\hline No & $28(5)$ \\
\hline \multicolumn{2}{|c|}{ Bloody nipple discharge } \\
\hline Yes & $25(4.3)$ \\
\hline No & $546(95.7)$ \\
\hline \multicolumn{2}{|c|}{ Ulceration/skin changes ${ }^{*}$} \\
\hline Yes & $38(6.7)$ \\
\hline No & $533(93.3)$ \\
\hline \multicolumn{2}{|l|}{ Bilaterality ${ }^{*}$} \\
\hline Yes & $27(4.7)$ \\
\hline No & $544(95.3)$ \\
\hline \multicolumn{2}{|l|}{ Tumor size* } \\
\hline Ts & $15(2.5)$ \\
\hline $\mathrm{T} 1$ & $105(17.7)$ \\
\hline $\mathrm{T} 2$ & $351(59.3)$ \\
\hline $\mathrm{T} 3$ & $94(15.9)$ \\
\hline $\mathrm{T} 4$ & $27(4.6)$ \\
\hline Unknown & 43 \\
\hline \multicolumn{2}{|c|}{ Nodal status** } \\
\hline NO & $184(31.7)$ \\
\hline N1 & $185(31.8)$ \\
\hline N2 & $126(21.7)$ \\
\hline N3 & $86(14.8)$ \\
\hline Unknown & 54 \\
\hline \multicolumn{2}{|l|}{ Stage ${ }^{* *}$} \\
\hline I & $63(12)$ \\
\hline$\|$ & $250(47.5)$ \\
\hline III & $168(31.9)$ \\
\hline IV & $45(8.6)$ \\
\hline Unknown & 109 \\
\hline
\end{tabular}

${ }^{*}$ Number of patients $=571$.

*Number of patients $=635$.

\section{Discussion}

The "Westernization" of the developing world has been claimed to be the main cause of the global rise in the prevalence of breast cancer. ${ }^{17}$ The increasing incidence of that disease among developing countries could be related to the higher predisposition to risk factors including early menarche, late menopause, nulliparity, late age at delivering the first child, exogenous hormone intake, postmenopausal obesity, and alcohol. ${ }^{1,2,18,19}$ The demographic and socioeconomic transitions witnessed by most countries in the EMR have increased the burden of cancer. ${ }^{20}$ It is believed that the difference in the impact of sociodemographic characteristics among the Arab countries could reflect economic variations in the implementation of the relevant health policies for cancer control. ${ }^{21}$ In general, the priority cancers in the region could be controlled provisionally though preventive and screening strategies; thus recommending effective interventions to tackle lifestyle risk factors. ${ }^{7,22}$ In general, regarding breast cancer it has been well documented that screening practices are suboptimum in the Arab world. ${ }^{23}$

\begin{tabular}{|c|c|c|c|}
\hline \multirow[t]{2}{*}{ Variable } & Age $<50$ & Age $\geq 50$ & Chi-square \\
\hline & $N(\%)$ & $N(\%)$ & P-value \\
\hline \multicolumn{3}{|l|}{ Marital status* } & 0.048 \\
\hline Single & $67(58.2)$ & $48(41.7)$ & \multirow{4}{*}{ Significant } \\
\hline Married & $473(45.8)$ & $559(54.2)$ & \\
\hline Divorced & $5(41.6)$ & $7(58.4)$ & \\
\hline Widow & $4(30.8)$ & $9(69.2)$ & \\
\hline \multicolumn{3}{|l|}{ Educational status ${ }^{*}$} & \multirow[t]{3}{*}{$<0.00001$} \\
\hline Illiterate & $93(35.5)$ & $169(64.5)$ & \\
\hline Primary school & $197(55.5)$ & $158(44.5)$ & \\
\hline Secondary school & $140(51.7)$ & $131(48.3)$ & \multirow[t]{3}{*}{ Significant } \\
\hline University and over & $101(44.9)$ & $124(55.1)$ & \\
\hline Unknown & $18(30.5)$ & $41(69.5)$ & \\
\hline \multicolumn{3}{|l|}{ Parity** } & \multirow[t]{2}{*}{$<0.00001$} \\
\hline Nulliparous & $48(41.7)$ & $67(58.3)$ & \\
\hline $1-2$ & $102(56.7)$ & $78(43.3)$ & \multirow{3}{*}{ Significant } \\
\hline $3-5$ & $251(50.6)$ & $245(49.4)$ & \\
\hline$\geq 6$ & $80(30.1)$ & $186(69.9)$ & \\
\hline \multicolumn{4}{|l|}{ Age at first child } \\
\hline$<20$ & $107(41.6)$ & $150(58.4)$ & \multirow[t]{2}{*}{0.138} \\
\hline $20-29$ & $217(46.6)$ & $249(53.4)$ & \\
\hline $30-35$ & $67(54)$ & $57(46)$ & \multirow{3}{*}{ Not significant } \\
\hline$>35$ & $35(49.3)$ & $36(50.7)$ & \\
\hline Unknown & $10(41.7)$ & $14(58.3)$ & \\
\hline \multicolumn{4}{|l|}{ Lactation $^{* * *}$} \\
\hline Yes & $252(46.4)$ & $291(53.6)$ & 0.809 \\
\hline No & $182(45.6)$ & $217(54.4)$ & Not significant \\
\hline \multicolumn{4}{|l|}{ Hormonal therapy* } \\
\hline Yes & $101(44.5)$ & $126(55.5)$ & 0.429 \\
\hline No & $448(47.4)$ & $497(52.6)$ & Not significant \\
\hline \multicolumn{4}{|c|}{ Family history (any cancer) $^{*}$} \\
\hline Yes & $166(49.3)$ & $171(50.7)$ & 0.293 \\
\hline No & $383(45.9)$ & $452(54.1)$ & Not significant \\
\hline \multicolumn{4}{|c|}{ Family history (breast cancer) ${ }^{*}$} \\
\hline Yes & $112(51.1)$ & $107(48.9)$ & 0.157 \\
\hline No & $437(45.9)$ & $516(54.1)$ & Not significant \\
\hline
\end{tabular}

Number of patients $=1172$.

"Number of patients $=1057$ (Unmarried are excluded).

**N Number of patients $=942$ (Unmarried and Nulliparous are excluded).

The mean age at diagnosis in this study was 51 years; $4.4 \%$ were younger than 35 years and $11 \%$ were over 64 years. Earlier research studies conducted on Iraqi women diagnosed with breast cancer have highlighted the relatively young age at presentation of the affected patients..$^{8-12,14,24}$ Similar observations were reported by other researchers from the region who proposed that the differences in the age at presentation of breast cancer between Arab and Western populations might be attributable to socioeconomic, demographic, and population factors. ${ }^{19,22,25}$ Upon monitoring health for sustainable development goals, WHO statistics confirmed that countries within the EMR have statistically younger population structures compared with the Western societies ${ }^{26}$; overall the age standardized incidence rates for breast cancer among Arab women are significantly lower. ${ }^{1}$ Focusing on Iraq a previous study, performed a decade 


\begin{tabular}{|c|c|c|c|}
\hline \multirow[t]{2}{*}{ Variable } & Age $>50$ years & Age $\geq 50$ years & Chi-square \\
\hline & $N(\%)$ & $N(\%)$ & $P$-value \\
\hline \multicolumn{4}{|c|}{ Palpable lump* } \\
\hline Yes & $274(50.4)$ & $269(49.5)$ & 0.289 \\
\hline No & $17(60.7)$ & $11(39.3)$ & Not significant \\
\hline \multicolumn{4}{|c|}{ Bloody nipple discharge* } \\
\hline Yes & $15(60)$ & $10(40)$ & 0.355 \\
\hline No & $276(50.4)$ & $270(49.5)$ & Not significant \\
\hline \multicolumn{4}{|c|}{ Ulceration/skin changes ${ }^{*}$} \\
\hline Yes & $20(52.6)$ & $18(47.4)$ & 0.831 \\
\hline No & $271(50.8)$ & $262(49.2)$ & Not significant \\
\hline \multicolumn{4}{|l|}{ Bilaterality $^{*}$} \\
\hline Yes & $16(59.2)$ & $11(40.7)$ & 0.382 \\
\hline No & $275(50.6)$ & $269(49.4)$ & Not significant \\
\hline \multicolumn{4}{|l|}{ Tumor size ${ }^{* *}$} \\
\hline Ts & $6(40)$ & $9(60)$ & 0.224 \\
\hline $\mathrm{T} 1$ & $56(53.3)$ & $49(46.7)$ & \\
\hline T2 & $174(49.6)$ & $177(50.4)$ & \\
\hline T3 & $58(61.7)$ & $36(38.3)$ & Not significant \\
\hline T4 & 25 (92.6) & $2(7.4)$ & \\
\hline Unknown & 19 & 24 & \\
\hline \multicolumn{4}{|c|}{ Nodal status"* } \\
\hline No & $90(48.9)$ & $94(51.1)$ & 0.584 \\
\hline $\mathrm{N} 1$ & $93(50.3)$ & $92(49.7)$ & \\
\hline N2 & $72(57.1)$ & $54(42.9)$ & Not sianificant \\
\hline N3 & $48(55.8)$ & $38(44.2)$ & Not signilicant \\
\hline Unknown & 27 & 27 & \\
\hline \multicolumn{4}{|l|}{ Stage $e^{* *}$} \\
\hline I & $33(52.3)$ & 30 (47.6) & 0.354 \\
\hline$\|$ & 118 (47.2) & $132(52.8)$ & \\
\hline III & 95 (56.5) & $73(43.4)$ & Not sianificant \\
\hline IV & $23(51.1)$ & $22(48.9)$ & ta \\
\hline Unknown & 61 & 48 & \\
\hline
\end{tabular}

Number of patients $=571$

*Number of patients $=635$.

earlier on 721 Iraqi female patients diagnosed with breast cancer, displayed that $45.9 \%$ presented after the age of 50 years and $75 \%$ were married $^{9}$; corresponding to $53.2 \%$ and $88 \%$ respectively in this study. That points out to a shift in the presentation of the disease toward postmenopausal age reflecting socioeconomic transitions. On the other hand, a study from Oman showed that out of 1230 examined breast cancer patients, $53.5 \%$ are still detected under the age of 50 years. ${ }^{27}$

This study illustrated that $19.2 \%$ of the studied cohort graduated from universities and only $10.8 \%$ were nulliparous whereas $7.5 \%$ had their first child born after the age of 35 years. While these figures were comparable to those recorded in earlier surveys on breast cancer among Iraqi women, ${ }^{9,12}$ the history of hormonal intake in the presented work (19.4\%) was significantly lower than that displayed by the Iraqi patients in 2010 (29\%) probably reflecting better orientation to the draw backs of such medications. ${ }^{9}$ Several studies have recorded a significant association between estrogen therapy and breast cancer among women with a family history. ${ }^{28}$ Longitudinal follow-up in a women's health initiative randomized trial revealed that family history and hormonal replacement therapy had independent and non-interacting effects on the risk of invasive breast carcinoma. ${ }^{29}$ In Iraq, a former comparative retrospective study involving 204 female patients diagnosed with breast cancer reported very close figures for positive history of cancer and breast cancer (30\% and $18.5 \%$ respectively) to those observed in this report; however, the demographic and clinical characteristics of patients with positive family history in that study did not reveal any distinct marker for their identification. ${ }^{30}$

Clinically, the vast majority (95\%) of Iraqi patients in this study presented with palpable lumps, one-third had axillary lymph node involvement; thus classifying $40.5 \%$ into advanced stages $(31.9 \%$ and $8.6 \%$ for stages III and IV respectively). Nevertheless, the rate for stage IV breast cancer was significantly lower than that was illustrated in a study conducted on patients visiting the same center in Baghdad 10 years ago ${ }^{9}$; obviously reflecting one of the promising outcomes of establishing the national program for early detection of breast cancer in Iraq in 2001..$^{10,12,24}$

A similar retrospective study performed on 1070 Egyptian breast cancer patients displayed that $18.7 \%$ were diagnosed before reaching 40 years, $79.5 \%$ were married, history of breast feeding, oral contraceptive pills, and breast cancer was noted in $73 \%, 39.5 \%$, and $7.5 \%$ respectively while $62 \%$ presented in stages III and IV. ${ }^{31}$ In India, the median age at presentation in a survey including 1528 breast cancer patients was 49 years, 69.6\% were postmenopausal, family history of breast cancer was positive in $4.2 \%$, the most common symptom was palpable lumps (96\%) and $57 \%$ were diagnosed in stages III and IV disease. ${ }^{32}$

On the other hand, in Croatia, Europe, where breast cancer is the most common type of female malignancy, analysis of the demographic characteristics and reproductive findings belonging to 870 female patients showed that the mean age was 69 years; $<2 \%$ were younger than 35 years. ${ }^{33}$ These findings were consistent with the results reported in other European studies. ${ }^{34}$ In the same Croatian survey, $8 \%$ were exposed to oral contraceptives, $15 \%$ were nulliparous with a mean number of children not exceeding 1.6, and only $5 \%$ delivered their first baby after the age of 35. Family history for breast and/or ovarian cancer was reported in 19\% and breast lump was the only presenting symptom in $95 \%$. In a comparative study on the clinical and pathological presentation of breast cancer among Iraqi and British women, the authors displayed that the patients were significantly younger in Iraq and presented with advanced stages; reflecting heterogeneity in the tumor biology and the dilemma of delayed diagnosis. ${ }^{14}$ Several other studies documented the existing gaps in the knowledge and practices toward breast cancer among the Iraqi society; emphasizing the necessity to elevate the level of awareness through strengthening public education campaigns and establishing national protocol guidelines for early detection, diagnosis and treatment of the disease. . $, 8,12,14,35-39^{-1}$

When correlating the impact of age, as an important risk factor, ${ }^{40}$ with the studied demographic and clinical features of breast cancer in this work no significant association was observed with the clinical stage at presentation. On the other hand, patients diagnosed with breast cancer at the age of 50 years and older were more likely to be married, illiterate and nulliparous compared to younger premenopausal patients $(p<0.05)$. Meta-analytic surveys focusing on breast cancer and reproductive variables in population-based studies 
confirmed that nulliparity, lactation and late age at first birth are significant independent determinants of breast cancer risk. $^{41,42}$ On the other hand, other studies from developing countries failed to emphasize that the age factor specifically at first child birth was significant. ${ }^{43}$ Among African-American patients, it was documented that age had a dual effect on parity as a risk factor; increasing the risk in women younger than 45 years and decreasing it among those 45 years and older; thus highlighting some of the factors responsible for the observed variations in the incidence of breast cancer in these societies. ${ }^{44}$

\section{Conclusion}

A considerable proportion of breast cancer patients in Iraq is still present with locally advanced disease at the time of diagnosis. That justifies the necessity to promote public awareness educational campaigns to strengthen our national early detection program. Excluding the marital status, level of education and number of parity, there was no statistical difference regarding the impact of age on the demographic and clinical profiles of breast cancer among premenopausal versus postmenopausal Iraqi patients.

\section{Acknowledgement}

The authors thank the working staff at the Main Referral Center for Early Detection of Breast Tumors, Oncology Teaching Hospital and the National Cancer Research Center, University of Baghdad for their assistance in providing the requested information.

\section{Author Contribution}

The principal corresponding author designed the study, analyzed the results, wrote the manuscript and presented the final version. The other authors supported in providing relevant information, data entry, and statistical analysis.

\section{Conflict of Interest}

The authors declare that they have no conflict of interest that competes with any of the contents of the manuscript.

\section{Funding}

None.

\section{References}

1. Bray F, Ferlay J, Soerjomataram I, Siegel RL, Torre LA, Jemal A. Global Cancer Statistics 2018: GLOBOCAN estimates of incidence and mortality worldwide for 36 cancers in 185 countries. Cancer J Clin. 2018;68:394-424.

2. Bray F, McCarron P, Parkin DM. The changing global patterns of female breast cancer incidence and mortality. Breast Cancer Res. 2004;6: 229-239.

3. Brinton LA, Gaudet MM, Gierach GL. Breast cancer. In: Thun MJ, Linet MS, Cerhan JR, Haiman CA, Schottenfeld D, Eds. Cancer Epidemiology and Prevention. 4th ed. New York, NY: Oxford University Press, 2018; pp. 861-888.

4. Annual Statistical Report 2016. Planning Directorate, Ministry of Health/ Environment, Republic of Iraq, 2017. Available from: https://moh.gov.iq/ upload/upfile/ar/513.pdf.

5. Annual Report. Iraqi Cancer Registry 2016. Iraqi Cancer Board, Ministry of Health and Environment, Republic of Iraq, 2018.

6. Alwan N, Al-Attar W, Eliessa R, Al-Midfaei Z, Nidhal F. Knowledge, attitude and practice regarding breast cancer and breast self-examination among a sample of the educated population in Iraq. East Mediterr Health J. 2012;18:337-345.

7. World Health Organization. Strategy for Cancer Prevention and Control in the Eastern Mediterranean Region 2009-2013, World Health Organization. Regional Office for the Eastern Mediterranean, 2010.

8. Alwan N. Iraqi initiative of a regional comparative breast cancer research project in the Middle East. J Cancer Biol Res. 2014;2:1016-1020.

9. Alwan NA. Breast cancer: demographic Characteristics and clinicopathological presentation of patients in Iraq. East Mediterr Health J. 2010:16:1059-1164.

10. Alwan NAS, Tawfeeq FN, Maallah MH, Sattar SA. The stage of breast cance at the time of diagnosis: correlation with the clinicopathological findings among Iraqi patients. J Neoplasm. 2017;2:1-10.

11. Alwan NAS, Mualla F, Al Naqash M, Kathum S, Tawfiq FN, Nadhir S. Clinical and pathological characteristics of triple positive breast cancer among Iraqi patients. Gulf J Oncolog. 2017;1:51-60.

12. Alwan NAS. Breast cancer among Iraqi women: Preliminary findings from a regional comparative breast cancer research project. J Glob Oncol. 2016:2:255-258.

13. Alwan NAS. Tumor characteristics of female breast cancer: pathological review of mastectomy specimens belonging to Iraqi patients. World J Breast Cancer Res. 2018;1:1-3.

14. Alwan NAS, Kerr D, Al-Okati D, Pezella F, Tawfeeq F. Comparative study on the clinicopathological profiles of breast cancer among Iraqi and British patients. Open Public Health J. 2018;11:177-191
15. NCCN Guidelines. NCCN Clinical Practice Guidelines in Oncology: Breast Cancer. V 1. 2016. National Comprehensive Cancer Network. Available from: http://www.nccn.org/professionals/physician_gls/pdf/breast.pdf.

16. Edge SB, Byrd DR, Compton CC, Fritz AG, Greene FL, Trotti A, Eds. AJCC (American Joint Committee on Cancer) Cancer Staging Manual. 7th ed. New York, NY: Springer-Verlag, 2010; pp. 347-377.

17. Porter P."Westernizing" women's risks? Breast cancer in lower-income countries. N Engl J Med. 2008;358:213-216.

18. Tfayli A, Temraz S, Abou Mrad R, Shamseddine A. Breast cancer in low- and middle-income countries: an emerging and challenging epidemic. J Oncology. 2010;2010:490631

19. Mehdi I, Monem EA, Al Bahrani BJ, Al Kharusi S, Nada AM, Al Lawati J, et al. Age at diagnosis of female breast cancer in Oman: issues and implications. South Asian J Cancer. 2014:3:101-106.

20. Ravichandran K, Al-Zahrani AS. Association of reproductive factors with the incidence of breast cancer in Gulf Cooperation Council countries. East Mediterr Health J. 2009;15:612-621

21. Sweileh WM, Zyoud SH, Al-Jabi SW, Sawalha AF. Contribution of Arab countries to breast cancer research: comparison with non-Arab Middle Eastern countries. BMC Womens Health. 2015;15:25.

22. Kulhanova I, Bray F, Fadhil I, Al Zahrani A, El Basmy A, Anwar W, et al. Profile of cancer in the Eastern Mediterranean region: the need for action. Cancer Epidemiol. 2017:47:125-132.

23. Donnelly TT, Khater AH, Al-Bader SB, Al Kuwari MG, Al-Meer N, Malik M, et al. Arab women's breast cancer screening practices: a literature review. Asian Pac J Cancer Prev. 2013;14:4519-4528.

24. Alwan N, Kerr D. Cancer control in war torn Iraq. Lancet Oncol. 2018:19:291292.

25. Najjar H, Easson A. Age at diagnosis of breast cancer in Arab nations. Int J Surg. 2010;8:448-452

26. World Health Organization. World Health Statistics 2017: Monitoring Health for the SDGs, Sustainable Development Goals, 2017. ISBN 978-924-156548-6.

27. Mehdi I, Monem EA, Bahrani BJ, Al Kharusi S, Nada AM, Al Lawati J, et al. Age at diagnosis of female breast cancer in Oman: issues and implications. South Asian J Cancer. 2014:3:101-106.

28. Dinger JC, Heinemann LA, Mohner S, Thai do M, Assmann A. Breast cancer risk associated with different HRT formulations: a register-based casecontrol study. BMC Womens Health. 2006;6:13.

29. Gramling R, Eaton CB, Rothman KJ, Cabral H, Silliman RA, Lash TL. Hormone replacement therapy, family history, and breast cancer risk among postmenopausal women. Epidemiology. 2009;20:752-756. 
30. Alwan NAS. Clinical and pathological characteristics of familial breast cancer in Iraq. Chron J Cancer Sci. 2017;1:002.

31. Gabr A1, Razek K, Atta H, Elsabah T, Tamam S. Demographic characteristics and clinico-pathological presentation of breast cancer female patients in South Egypt Cancer Institute (2005-2012). SECI Oncol. 2016;1-6.

32. Velappan A, Shumugam D. Analysis of demographic characteristics and treatment outcome of breast cancer patients in a tertiary cancer centre. IOSR J Dent Med Sci. 2017;16:25-28.

33. Zitnjak D, Soldić Z, Kust D, Bolanča A, Kusić A. Demographic and clinicopathologic features of patients with primary breast cancer treated between 1997 and 2010: a single institution experience. Acta Clin Croat. 2015:54:295-302

34. OECD. Health at a Glance: Europe 2012. OECD Publishing, 2013;24-26.

35. Al Alwan N. Establishing guidelines for early detection of breast cancer in Iraq. Int J Adv Res. 2015;3:539-555.

36. Sankaranarayanan R, Alwan N, Denny L. How can we improve survival from breast cancer in developing countries? Breast Cancer Manage. 2013;2:179183.

37. Alwan NAS, Al-Attar WM. Evaluating the effect of an educational teaching model on the knowledge about breast cancer among female university students in Iraq. JJ Cancer Sci Res. 2016;2:026.
38. Alwan NAS, Al-Attar WM, Mallah N, Hassoun T. Baseline needs assessment for breast cancer awareness and management among paramedical health care providers in Iraq. Int J Sci Res. 2017;6:1515-1519.

39. Alwan NAS, Al-Attar WM, Al Mallah. Baseline needs assessment for breast cancer awareness among patients in Iraq. Int J Sci Res. 2017;6:20882093.

40. Chen HL, Zhou MQ, Tian W, Meng KX, He HF. Effect of age on breast cancer patient prognoses: a population-based study using the SEER 18 database. PLoS One. 2016;11:e0165409.

41. Ewertz M, Duffy SW, Adami HO, Kvale G, Lund E, Meirik O, et al. Age at first birth, parity and risk of breast cancer: a meta-analysis of 8 studies from the Nordic countries. Int J Cancer. 1990;46:597-603.

42. Babalou A. The association of parity and breastfeeding with breast cancer: $a$ review. Health Sci J. 2017;11:1.

43. Huo D, Adebamowo CA, Ogundiran TO, Akang EE, Campbell O, Adenipekun A, et al. Parity and breastfeeding are protective against breast cancer in Nigerian women. Br J Cancer. 2008;98:992-996.

44. Palmer JR, Wise LA, Horton NJ, Adams-Campbell LL, Rosenberg L. Dual effect of parity on breast cancer risk in African-American women. J Natl Cancer Inst. 2003;95:478-483. 